\title{
Topical propranolol and ocular tension in the human
}

\author{
J. VAlE, A. C. G. GIBBS, And G. I. PHILLIPS* \\ From the Departments of Pharmacology, Social and Preventive Medicine, and Ophthalmology, \\ University of Manchester
}

Propranolol was introduced as a $\beta$-adrenergic receptor antagonist, having about ten times the potency of pronethalol against isoprenaline (Black, Crowther, Shanks, Smith, and Dornhorst, I964) while being devoid of intrinsic sympathomimetic activity.

A preliminary investigation with systemic racemic propranolol intravenously and by mouth showed that it caused a lowering of ocular tension in patients with glaucoma (Phillips, Howitt, and Rowlands, 1967). These observations were confirmed by Coté and Drance (1968) using orally administered propranolol in humans, and by Vale and Phillips (1970) using intravenously administered propranolol in humans and rabbits. Following reports that topical propranolol was also effective in reducing tension (Bucci, Giraldi, Missiroli, and Virno, I968), it was decided to reinvestigate the effect of topical propranolol; a previous, unpublished trial with propranolol in humans had given disappointing results, particularly when it was compared with the effects of topical propranolol in the rabbit (Vale, I968).

\section{Method}

The investigation was carried out for a period of 4 days on ten patients, six male and four femalc, aged 47 to 82 years. This group included three patients with bilateral open-angle glaucoma, five with bilateral ocular hypertension, one with unilateral ocular hypertension, and one with chronic closed-angle glaucoma; in the last, a left sector iridectomy and a right iris inclusion had been done. Seven of the patients had received no previous treatment and in the remaining three treatment was stopped at least 48 hours before the investigations with propranolol began. Table I gives details of the patients' diagnoses and previous treatments.

Table I Details of patients in the trial

\begin{tabular}{|c|c|c|c|c|}
\hline Patient & Sex & $\begin{array}{l}\text { Age } \\
(y r s)\end{array}$ & Diagnosis & Previous medical treatment \\
\hline A & $\mathrm{F}$ & $5^{6}$ & Bilateral ocular hypertension & None \\
\hline B & $\mathrm{F}$ & 65 & Bilateral ocular hypertension & None \\
\hline C & $\mathbf{M}$ & 60 & Bilateral chronic closed angle-glaucoma & None \\
\hline $\mathrm{D}$ & $\mathbf{M}$ & $5^{6}$ & Bilateral ocular hypertension & None \\
\hline E & $\mathbf{M}$ & 47 & Bilateral open-angle glaucoma & 2 per cent. pilocarpine, three times daily \\
\hline $\mathrm{F}$ & $\mathbf{M}$ & 64 & Bilateral ocular hypertension & $\begin{array}{l}\text { I per cent. pilocarpine, three times daily } \\
\text { I per cent buffered adrenaline, at night }\end{array}$ \\
\hline G & $\mathbf{M}$ & 63 & Bilateral ocular hypertension & None \\
\hline $\mathrm{H}$ & $\mathbf{F}$ & 73 & Bilateral open-angle glaucoma & None \\
\hline I & $\mathbf{M}$ & 55 & Right ocular hypertension & 4 per cent. pilocarpine, three times daily \\
\hline $\mathrm{J}$ & $\mathrm{F}$ & 82 & Bilateral open-angle glaucoma & None \\
\hline
\end{tabular}


The trial was arranged in a double-blind, cross-over pattern, each patient acting as his own control. On the first day one eye (left or right), chosen at random, received drops of propranolol i per cent., the other eye receiving drops of vehicle. For both eyes readings of ocular tension (by applanation tonometry) were made at 9.30, 10.00, 10.30, and I1.00 a.m., 12.00 noon, 1.30, 2.00, 2.30, 3.00, 4.00 , and $5.30 \mathrm{p} . \mathrm{m}$. One drop of propranolol or vehicle was instilled into the chosen eye immediately following the $9.30,1.30$, and 5.30 readings. The same allocation of drops was made on the second day (i.e. the eye that received propranolol on the first day also received it on the second day). On the third day the allocation of propranolol and vehicle was reversed. This regimen was repeated exactly on the fourth day. Thus the eye receiving propranolol on the first two days received vehicle on the third and fourth days and vice versa.

PREPARATIONS USED

All drops were prepared by the Pharmacy Department of Manchester Royal Infirmary. Propranolol drops contained propranolol hydrochloride I per cent., citric acid 0.3 per cent., sodium chloride $0 \cdot 5$ per cent., sodium hydroxide to $\mathrm{pH} 6 \cdot 5$. The vehicle had the same composition with the exception of the propranolol.

\section{Analysis of results}

A reading of ocular tension in any one patient will be influenced by several factors: which of the two eyes is used for the reading, the day of the investigation, the time of day, and the treatment (propranolol or vehicle) received by the eye. This investigation was designed to determine whether there existed a statistically significant difference in the tension as a result of the treatment received: such a determination, however, must take into account and allow for the other factors involved.

To make the analysis possible, it has had to be assumed that the mean changes in ocular tension after propranolol drops were the same on each of the 4 days of the trial, and were the same in both the right and the left eyes; similarly for the vehicle.

It is then assumed that a particular reading of ocular tension can be expressed by the sum of five quantities as follows:

$$
y_{i j k l}=\mu+\alpha_{i}+\beta_{j}+\gamma_{k l}+e_{i j k l},
$$

where $y_{i j k l}$ is the ocular tension and $i, j, k, l$, indicate respectively the eye, the day, the time, and the treatment.

$$
\begin{aligned}
& \mu=\text { mean ocular tension for the given individual } \\
& \alpha_{i}=\text { effect of the differences between left or right eye on the ocular tension, } i=1,2 \\
& \beta j=\text { effect of the difference between the days on the ocular tension, } j=1,2,3,4 \\
& \gamma_{\mathrm{kl}}=\text { effect of the time and the effect of propranolol or vehicle on the ocular tension } \\
& \mathbf{k}=\mathbf{I}, 2 \ldots \ldots \ldots \ldots \ldots \ldots \ldots \ldots \ldots \ldots \ldots
\end{aligned}
$$

For the measurements in the eye which had received propranolol, its effect at a particular time can be subdivided into $(a)$ the effect of the propranolol plus $(b)$ the effect of the vehicle. The null hypothesis is that the effect of the propranolol is zero.

The success of any model representing the situation is measured by obtaining from the results estimates of the parameters involved, substituting these estimates back in the original equation, and calculating the sum of the squares of the residual, known as the residual variation,

$$
\Sigma_{\mathbf{i j k l}} \mathrm{e}^{\mathbf{2}_{\mathrm{ijk} \mathbf{l}}}
$$


This will of course be partly dependent, among other things, on the total number of results obtained and on the number of parameters fitted. To obtain a measure of the residual variation independent of the total number of results and the number of parameters fitted, we calculate $\Sigma_{i j k l} \mathrm{e}^{2_{i j k l}}$ divided by the total number of results less the number of parameters fitted.

If the effect of propranolol were zero, a certain function of the two measures of residual variation would have values given by an $\mathrm{F}$ distribution. If, on the other hand, the effect were not zero, this function of the two values of the residual variation would have values given by another distribution which would tend to result in values higher than those given by the $\mathrm{F}$ distribution.

We have used this analysis to obtain estimates of the changes which are due to the effect of propranolol (independently of the other effects already mentioned), and to find the time at which propranolol has its maximum effect.

\section{Results}

Table II shows the $\mathrm{F}$ values obtained for each patient, together with the level of significance of the effect of the propranolol. The Table also shows the maximum fall produced in each patient and the time at which it occurred. From this Table, propranolol produced a significant $(\mathrm{P}<0 \cdot 005)$ lowering of the ocular tension in seven $(A, C, D, E, F, G, H)$ of the ten individuals studied. In two of the patients, $\mathrm{D}$ and $\mathrm{J}$, the maximum fall occurred after the first instillation of the drops, i.e. at I.30 p.m. In all other cases, the maximum fall was achieved after the second instillation, at times ranging between 2.00 p.m. and 5.30 p.m., i.e. $30 \mathrm{~min}$. to $4 \mathrm{hrs}$ after the second dose with a mean of $1 \frac{3}{4}$ hours.

Fig. I shows the mean fall in ocular tension produced by propranolol in all ten indi viduals, and the mean fall in tension produced by propranolol in the seven individuals ino whom the effect was significant. The graphs show a fairly steep initial fall in tension followed by a slower fall. After the second administration of propranolol (1.30 p.m.) the tension again shows an initial steeper rate of fall. At the final reading (5.30 p.m.) the tension appears to be beginning to rise again.

Table II $F$ values, maximum falls, and significance of results for the ten patients

\begin{tabular}{|c|c|c|c|c|c|}
\hline Patient & $\begin{array}{l}\text { Maximum } \\
\text { fall } \\
(\mathrm{mm} . \mathrm{Hg})\end{array}$ & $\begin{array}{l}\text { Time of } \\
\text { maximum } \\
\text { fall }\end{array}$ & $\begin{array}{l}\text { Total number } \\
\text { of readings } \\
\text { of tension }\end{array}$ & $F$ value* & Significance* \\
\hline A & $3 \cdot 50$ & 2.00 p.m. & 88 & $7 \cdot 48$ & $\mathrm{P}<0.005(\mathrm{~S})$ \\
\hline B & $I \cdot 50$ & 4.00 p.m. & 80 & $\mathrm{I} \cdot 02$ & $P>0.05 \quad$ (N.S) \\
\hline $\mathbf{C}$ & $4 \cdot 00$ & 3.00 p.m. & 88 & $6 \cdot 29$ & $\mathrm{P}<0.005(\mathrm{~S})$ \\
\hline D & $4 \cdot 25$ & I.30 p.m. & 88 & $5 \cdot 48$ & $\mathrm{P}<0.005(\mathrm{~S})$ \\
\hline $\mathbf{E}$ & $6 \cdot 50$ & 3.0o p.m. & 80 & $3 \cdot 65$ & $\mathrm{P}<0.005(\mathrm{~S})$ \\
\hline $\mathrm{F}$ & $4 \cdot 5^{\circ}$ & 2.30 p.m. & 80 & $14 \cdot 18$ & $\mathrm{P}<0.005(\mathrm{~S})$ \\
\hline G & $6 \cdot 00$ & 4.00 p.m. & 88 & $18 \cdot 16$ & $\mathrm{P}<0.005(\mathrm{~S})$ \\
\hline $\mathbf{H}$ & $5 \cdot 00$ & 2.30 p.m. & 88 & $3 \cdot 38$ & $\mathrm{P}<0.005(\mathrm{~S})$ \\
\hline I & $3 \cdot 50$ & 5.30 p.m. & 88 & $1 \cdot 62$ & $\mathrm{P}>0.05 \quad$ (N.S) \\
\hline $\mathrm{J}$ & $4 \cdot 75$ & I.30 p.m. & 88 & 1.19 & $\mathrm{P}>0.05 \quad(\mathrm{~N} . \mathrm{S})$ \\
\hline
\end{tabular}

* The $F$ value was tested with 9 and 57 degrees of freedom for patients $B, E$, F, and with 10 and 63 for all other patients.

$\mathrm{S}=$ significant. $\quad \mathrm{N} . \mathrm{S}=$ non-significant. 


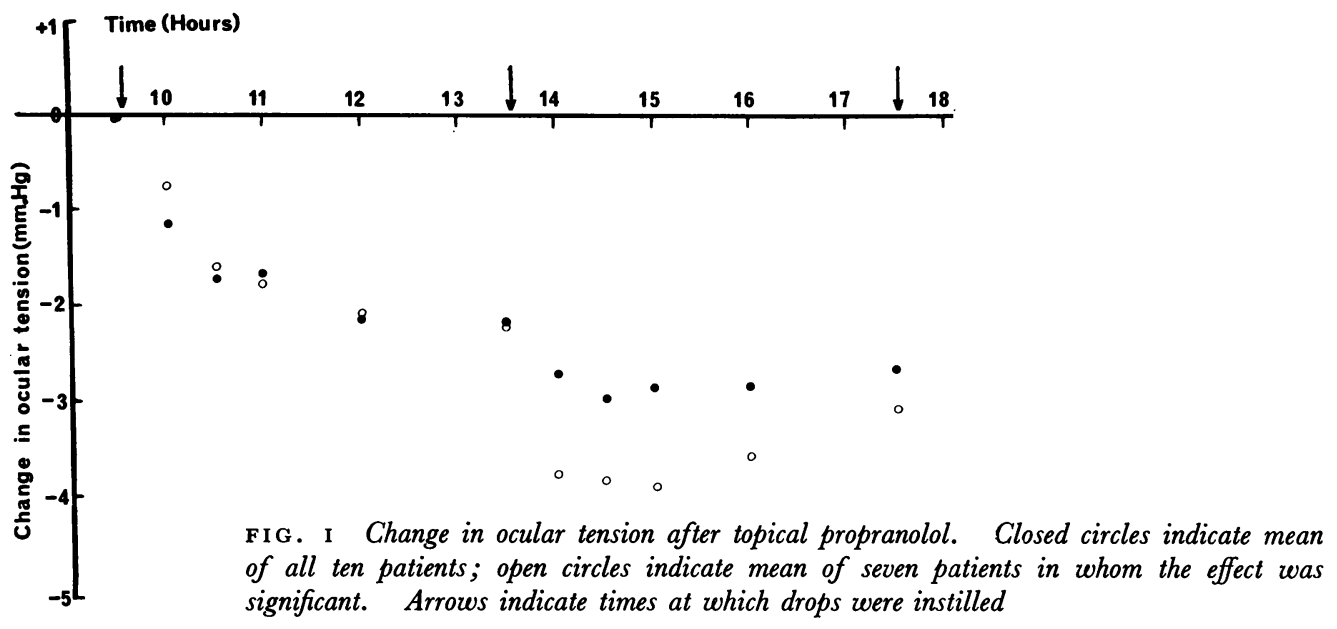

\section{Discussion}

The results show that propranolol administered in the form of eye drups exerts a significant, although not marked, lowering effect on the ocular tension. The greatest fall in tension achieved in any patient at any time was $6.5 \mathrm{~mm}$. $\mathrm{Hg}$; the poorest responder showed a maximum fall of $\mathrm{I} \cdot 5 \mathrm{~mm}$. $\mathrm{Hg}$ : the mean of the maximum falls was $4.35 \mathrm{~mm}$. $\mathrm{Hg}$.

PATIENTS: "NON-SIGNIFICANT"

The three patients who did not show a significant reduction in tension were $B$, $I$, and J. During the vehicle treatment of patient $B$, who had bilateral ocular hypertension, the tension range in the right eye was 16 to $20 \mathrm{~mm}$. $\mathrm{Hg}$, and in the left 15 to $20 \mathrm{~mm}$. $\mathrm{Hg}$. These fairly low tensions may make it more difficult to achieve a significant fall. However other patients ( $\mathrm{A}$ and $\mathrm{G}$ ) with equally low tensions and the same diagnosis did show significant falls with propranolol.

Patient I had ocular hypertension in one eye only, with a tension range of 30 to $42 \mathrm{~mm}$. $\mathrm{Hg}$ during treatment with vehicle, whereas the other eye had a range of 12 to $18 \mathrm{~mm} . \mathrm{Hg}$. For propranolol to give a statistically significant result in the face of this difference between the two eyes, and the wide tension range in the affected eye, a very large fall in tension would be required. The maximum fall achieved was $3.5 \mathrm{~mm} . \mathrm{Hg}$; this same fall in patient A gave a significant result. There was also a second factor which could have worked against a significant result in this patient. Before the trial with propranolol, he had been receiving pilocarpine 4 per cent. in the affected eye, but this treatment was withdrawn 48 hours before the trial began. In the randomization of drops it happened that this affected eye received propranolol on the first two days followed by vehicle on the second two. It is possible that the pilocarpine could still have been exerting some tension lowering effect at the beginning of the trial, which gradually decreased, with a resultant rise in tension, as the trial progressed, with a consequent masking of the effect of propranolol.

Patient $\mathrm{J}$ had bilateral open-angle glaucoma with a tension range during vehicle treat-

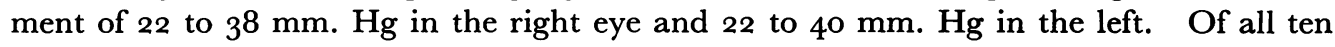
patients this one had the highest "residual" variation, a fact which possibly explains why the maximum lowering of $4 \cdot 75 \mathrm{~mm}$. $\mathrm{Hg}$ did not give a significant result. 
PATIENTS: "SIGNIFICANT"

Of the seven patients who did show a significant result, four had ocular hypertension, two had bilateral open-angle glaucoma, and one had bilateral chronic closed-angle glaucoma.

From the time course in Fig. I, it is clear that the instillation of propranolol drops causes at first a rapid rate of fall in tension which then slows until the second instillation when there is again a rapid fall. This fall after the second instillation suggests that the initial instillation did not produce a maximum effect on the tension. In view of this it would be of interest to observe the effect of several instillations made over a short period, say half an hour, to determine if this would produce a different time course. (The concentration of the drops cannot be increased to obtain a greater effect because of irritation, and therefore loss of drug with watering). Even with I per cent. drops, patients complained of considerable stinging. The two-phase fall in tension after the first instillation of drops suggests that propranolol may have two different actions; evidence for this has already been published (Vale and Phillips, i970).

Because propranolol may have a role in the management of glaucoma, at least as an adjunct to other treatment, a preliminary assessment of its long-term effects was made. Some out-patients used propranolol drops for several months in one eye only, and they returned as in-patients for several days for tonometry during a period of replacement of the propranolol drops by vehicle. Of the three patients examined, one showed intense local allergic reaction to the drops which made it difficult to draw any conclusions regarding the tension effect of propranolol, while a second patient had used the drops only intermittently because of a nasal operation during the period concerned. The third patient did show some rise in tension after withdrawal of propranolol, the average tension in the eye receiving propranolol being $20 \mathrm{~mm}$. $\mathrm{Hg}$ and after withdrawal $23 \mathrm{~mm}$. $\mathrm{Hg}$ (Fig. 2); in the eye which had not received propranolol, the pressure actually fell from an average of $20 \mathrm{~mm}$. $\mathrm{Hg}$ to one of $18.5 \mathrm{~mm}$. Hg over the period of follow-up. This is some indication that propranolol was still producing some reduction in tension after $8 \frac{1}{2}$ months of use.

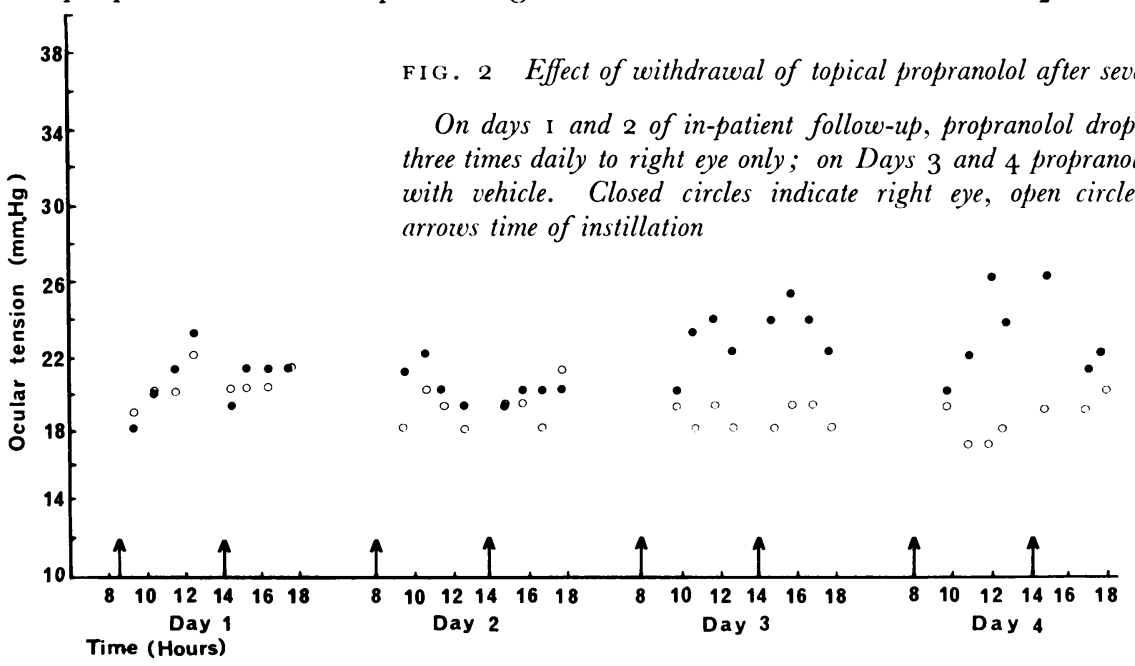

\section{Summary and conclusion}

A trial of I per cent. propranolol eye drops in a group of patients with glaucoma or ocular hypertension clearly demonstrates that the drug exerts a significant though not marked 
reducing effect on intraocular pressure. Propranolol may prove to be a useful adjunct to the medical treatment of glaucoma if a long-term effect can be proven. Two disadvantages to its routine use are the stinging and irritation (in one case a probable allergic reaction) produced and the local anaesthetic effect on the cornea.

We are grateful to I.C.I. (Pharmaceuticals) Ltd. for generous supplies of propranolol, and to Miss C. E. Ashcroft, of the Pharmacy Department, Manchester Royal Infirmary, for invaluable help in preparing solutions.

\section{References}

BlACK, J. W., Crowther, A. F., Shanks, R. G., SMith, L. H., and Dornhorst, A. c. (i964) Lancet, I, 1080

BUCci, M. G., Giraldi, J. PEcori, missiroli, A., and virno, m. (ig68) Boll. Oculist., 47, $5^{\mathrm{I}}$

Coté, G., and Drance, s. M. (ig68) Canad. 7. Ophthal., 3, 207

Phillips, c. I., howitt, G., and Rowlands, D. J. (1967) Brit. J. Ophthal., 51, 222

vale, J. (I 968) M.Sc. Thesis, Manchester

-_ and Phillips, c. I. (I970) Exp. Eye Res., 9, 82 